
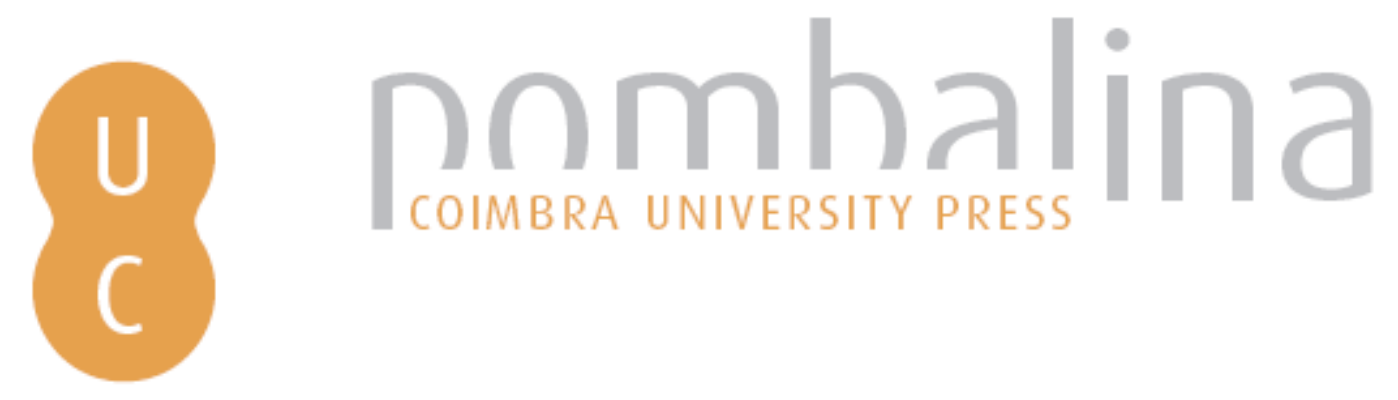

O que é um clássico?: variações sobre J. M. Coetzee
Autor(es): $\quad$ Silvestre, Osvaldo Manuel
Publicado por: Imprensa da Universidade de Coimbra
URL
persistente: URI:http://hdl.handle.net/10316.2/38711
DOI: $\quad$ DOI:http://dx.doi.org/10.14195/978-989-26-1164-8_34

Accessed : $\quad$ 26-Apr-2023 12:14:21

A navegação consulta e descarregamento dos títulos inseridos nas Bibliotecas Digitais UC Digitalis, UC Pombalina e UC Impactum, pressupõem a aceitação plena e sem reservas dos Termos e Condições de Uso destas Bibliotecas Digitais, disponíveis em https://digitalis.uc.pt/pt-pt/termos.

Conforme exposto nos referidos Termos e Condições de Uso, o descarregamento de títulos de acesso restrito requer uma licença válida de autorização devendo o utilizador aceder ao(s) documento(s) a partir de um endereço de IP da instituição detentora da supramencionada licença.

Ao utilizador é apenas permitido o descarregamento para uso pessoal, pelo que o emprego do(s) título(s) descarregado(s) para outro fim, designadamente comercial, carece de autorização do respetivo autor ou editor da obra.

Na medida em que todas as obras da UC Digitalis se encontram protegidas pelo Código do Direito de Autor e Direitos Conexos e demais legislação aplicável, toda a cópia, parcial ou total, deste documento, nos casos em que é legalmente admitida, deverá conter ou fazer-se acompanhar por este aviso.

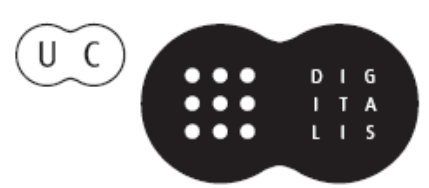


Osvaldo Manuel Silvestre

Universidade de Coimbra / Centro de Literatura Portuguesa

\section{O QUE É UM CLÁSSICO? VARIAÇÕES SOBRE J. M. COETZEE}

1. No ensaio "What Is a Classic? A Lecture» ${ }^{1}$, o escritor sul-africano J. M. Coetzee narra o episódio do seu "encontro com o clássico", em termos que prefiro não parafrasear:

Numa tarde de domingo do Verão de 1955, tinha eu 15 anos, vagueava pelo jardim das traseiras da nossa casa nos subúrbios da Cidade do Cabo, interrogando-me sobre o que fazer, já que o tédio era então o maior problema da minha existência, quando, da casa ao lado, ouvi música. Enquanto a música durou fiquei imóvel, sem me atrever a respirar. A música falava comigo como nunca antes o fizera. (Coetzee, 1993: 9)

O que o jovem Coetzee ouvia, deslumbrado, era O Cravo bem temperado, de Bach. Sucede porém que o jovem Coetzee provinha de uma família sem cultura musical, o que não obstou, ainda assim, a esse "momento de revelação» (id.: 10). Nas suas palavras, "pela primeira vez eu sofria o impacto do clássico" (id.). Coetzee, aliás, não é parco nas palavras: "A revelação no jardim foi um evento decisivo na minha formação» (id.).

Coetzee deseja, com o ensaio, interrogar de novo esse momento irrepetível do seu encontro com Bach, isto é, com o clássico. A interrogação é dupla e resumo-a assim: (i) Em que sentido pode Coetzee dizer, se é que pode, que o espírito de Bach comunicou consigo por sobre as eras e os contextos? (ii) Muito

1 O ensaio foi lido, como conferência, em Graz, Áustria, em 1991, tendo sido reunido em livro pela primeira vez em 1993. A tradução que proponho é de minha autoria. 
ao invés, não estaria ele, naquele momento, a eleger simbolicamente a alta cultura europeia, e o domínio dessa cultura, como um instrumento que o arrastasse para fora de uma situação provincial e bloqueada, na África do Sul? Por outras palavras, tratou-se de uma experiência de encontro desinteressado e «impessoal» com a obra de arte, ou tudo não passou da «expressão mascarada» de um interesse material?

Ora, em que sentido é Bach um clássico? Coetzee responde: Bach é clássico por ser (i) intemporal, isto é, por possuir sentido para épocas diversas; por (ii) uma parte significativa da sua música integrar o cânone musical europeu, ou seja, o repertório musical diariamente executado na Europa e não apenas; finalmente, (iii) Bach não é um clássico (é um barroco) por não integrar o classicismo que dominará a arte europeia a partir do segundo quartel do século xviII. Coetzee lembra que Bach era demasiado velho e antiquado para a estética musical nascente: as próprias autoridades da igreja de Leipzig em que exercia funções ficaram aliviadas com a sua morte e contrataram um compositor bem mais jovem e mais sintonizado com os novos tempos (valorização da melodia em detrimento do contraponto, unidade, simplicidade, clareza e decoro em vez de complexidade arquitetónica, privilégio do sentimento sobre o intelecto, etc.).

O que sucedeu após a sua morte é conhecido: Bach, já um compositor obscuro em vida, sobretudo nos seus últimos anos, caiu no esquecimento durante cerca de oitenta anos, vindo apenas a ser "ressuscitado» devido ao entusiasmo de alguns aficionados, com especial destaque para Felix Mendelssohn. Ou seja, se Bach é um clássico, é-o em versão estranha, pois antes do "Bach revival» foi um clássico invisível. Como diz, com justeza, Coetzee, «Ele não apenas foi não-canónico, ele não existia publicamente» (id.: 13).

Se o clássico não conhece limites - os do tempo e do espaço - como entender o caso de Bach? Tudo indica que Bach, enquanto clássico, foi historicamente construído, num contexto em que o nacionalismo e o protestantismo alemães usaram o seu nome em reação a Napoleão. Bach ajuda a promover o nacionalismo e o protestantismo alemães e, em sentido inverso, estes promovem-no a clássico. O Romantismo, com o seu entusiasmo pela música absoluta como forma privilegiada de comunicação direta entre belas almas, fornece uma legitimação suplementar. Todo este processo, enfim, se conclui em 1829, quando Mendelssohn dirige em Berlim as famosas execuções da Paixão segundo S. Mateus. 
As performances da Paixão segundo S. Mateus, diz-nos Coetzee, "eram poderosamente históricas de uma maneira largamente invisível para os espíritos que por trás delas se agitavam» (id.: 14). Coetzee tenta chegar a um ponto intermédio entre a historicização e a subtração do clássico ao tempo, defendendo que o Bach romântico tanto era o produto de homens e mulheres que reagiam à música da mesma forma incondicionada que ele experienciara em 1955, no jardim das traseiras da sua casa, como «O produto de uma vaga de sentimento comunitário que encontrou em Bach um veículo para a sua própria expressão» (id.: 15). Ao interrogar historicamente a sua experiência de 1955 - o seu encontro com o clássico -, Coetzee coloca então uma questão decisiva:

E o que significa dizer que o clássico me falava em 1955 quando o sujeito que coloca esta questão reconhece que o clássico - para não dizer o sujeito - é historicamente constituído? (id.)

Se a conceção intemporal do clássico é abalada pela reconstituição do processo da receção de Bach, pergunta-se Coetzee, será que o momento no jardim é também posto em causa? «Será que falarem connosco por sobre as idades é uma noção que hoje só podemos usar com má-fé?» (id.: 16).

Esclareça-se que Coetzee está interessado em responder negativamente a esta pergunta, razão pela qual irá desmistificar o «ocaso» post mortem de Bach: se ele era assim tão obscuro, como pôde Mendelssohn conhecer a sua música? A resposta é também hoje conhecida: Bach nunca caiu inteiramente no esquecimento pois um círculo de músicos, em Berlim, executou regulamente a sua música em privado. O embaixador da Áustria em Berlim frequentou esse círculo e, de volta à sua capital, levou consigo transcrições de Bach que fez executar em sua casa. Um dos frequentadores do seu círculo vienense foi Mozart, que também fez cópias das transcrições de Bach e chegou a estudar a Arte da Fuga. Um outro membro desse círculo foi Haydn. Ou seja, existiu sempre um culto de Bach, ainda que limitado. Limitado em grande medida a especialistas, esclareça-se. Aqui chegados, torna-se necessário ouvir de novo Coetzee: 
Digo que interessava apenas a especialistas (ou profissionais). Este é o ponto em que os paralelos entre a literatura e a música, entre os clássicos literários e os clássicos musicais começam a soçobrar, e em que as instituições e a prática da música emergem como talvez mais saudáveis do que as instituições e a prática da literatura. (id.: 17)

É curioso que Coetzee afirme ser este o momento em que «o paralelo entre literatura e música, entre os clássicos literários e os clássicos musicais» começa a ruir, pois é bem provável que só agora nos ocorra que Coetzee está a tentar produzir um tal paralelo... De facto, Coetzee esteve sempre a falar de um caso - o do seu encontro com o clássico, na pessoa de Bach - que lhe serviu, antes de mais, para muito deliberadamente suspender o paralelo com a literatura. Lembremos que o ensaio de Coetzee herda o título, e o precedente, de um famoso ensaio de T. S. Eliot, "What Is a Classic?», lido também como conferência, em 1944, à Virgil Society em Londres. Nesse ensaio, Eliot interroga-se sobre o clássico, defendendo que a civilização europeia é uma só, sendo o fundamento dessa unicidade a Igreja de Roma, o latim e, lá mais ao fundo, sobre um pedestal, o autor clássico - Virgílio - e a obra que funciona como o clássico originário dessa civilização destinada a império: a Eneida, realização sazonada de uma civilização madura (e a maturidade civilizacional seria a condição orgânica da existência do clássico). Ora, na primeira parte do seu ensaio, Coetzee descreve o ensaio de Eliot, bem como o seu contexto pessoal e epocal, centrando-se nas estratégias ativadas pelo poeta anglo-americano para reivindicar uma identidade mais europeia do que a dos europeus de nascença. A forma como Coetzee lê em Eliot a dramatização da sua condição de americano errante ansiando pela metrópole é muito congruente com a sua condição de sul-africano branco vitimado pelo clássico na experiência epifânica de 1955. Ou seja, Coetzee produz uma revisão pós-colonial dos dilemas de Eliot, em si tão coloniais, para não dizer imperiais; e, para essa releitura, o episódio-Bach é decisivo, pois ele suscita no sujeito vitimado um manifesto desejo de afiliação numa tradição - artística e civilizacional - de que o clássico é aqui um epítome.

Porque a ideia do clássico é europeia, a ponto de podermos dizer que a Europa é a civilização dos clássicos e, como se isso não bastasse, a civilização clássica. Estas afirmações, porém, são hoje chocantemente etnocêntricas: o clássico 
é hoje, enfim, universal; mas precisamente por esse se ter revelado o telos da ideia de clássico, percebemos que ela se desreferencializou ao ponto de se tornar conceptualmente impertinente. Em todo o caso, o ensaio de Coetzee situa-nos ainda no quadro de referência civilizacional tradicional do clássico - «Bach, um grande europeu» - mas infetando-o do interior com o vírus pós-colonial, que aqui significa muito literalmente «um conjunto antinómico de consequências da colonização». O nome "África do Sul» condensa tais consequências e antinomias na forma daquilo a que poderemos chamar um tropo - o tropo mais recorrente em Coetzee - da incoincidência entre locus e cultura(s). O sujeito vitimado por Bach é um sujeito de súbito sem lugar, condenado a uma situação que Homi Bhabha designaria in-between. Neste sentido, o clássico não enraíza o sujeito numa tradição unitária, como desejaria Eliot, mas move-o para um espaço que Coetzee parece desejar que fosse ainda transcendental - mas é apenas pós-colonial, isto é, histórico. Lembro que Coetzee explica a falta de cultura musical clássica na sua família com o argumento de que «nas colónias a música clássica era maricas» (id.: 9). E todo o seu esforço para situar a questão da música clássica ao tempo da sua experiência originária no jardim redunda na sua tradução geográfica (e geopolítica e geocultural): "A chamada componente clássica dessa cultura musical [a das ex-colónias britânicas] pode ter sido europeia na origem, mas era uma Europa mediada e num certo sentido orquestrada pelos Boston Pops» (id.: 10). O universal implicado na exposição desprotegida à música de Bach é, pois, logo a seguir, traduzido em global. E, como diria Stuart Hall,

'Global' neste sentido não significa universal, nem tampouco é algo específico a alguma nação ou sociedade. Trata-se de como as relações transversais e laterais que Gilroy denomina 'diásporicas' (...) complementam e ao mesmo tempo deslocam as noções de centro e periferia, e de como o global e o local reorganizam e moldam um ao outro. (Hall, 2003: 109)

Notemos que, onde Eliot tenta subalternizar as suas origens americanas em favor de uma «descendência proveniente menos dos Eliots da Nova Inglaterra e/ ou de Somerset do que de Virgílio e Dante, ou pelo menos de uma descendência na qual os Eliots são um rebento excêntrico da grande ascendência Virgílio-Dante» (Coetzee, id.: 7), Coetzee apresenta-nos uma cena primitiva suburbana, na Cidade 
do Cabo. A sua relação com o clássico é estranhamente função daquele lugar: um jardim nas traseiras da casa. E é essa função, e a possibilidade de o clássico o teletransportar numa viagem para lugar nenhum, que Coetzee deseja interrogar no seu ensaio. Permitam-me algumas notas a respeito disto:

(i) O jardim das traseiras é a marca da contingência do clássico. É necessário estar naquele local, num certo dia de 1955, para se ser vitimado por ele. Porém, no mesmo jardim, a forma como Bach vitima o jovem Coetzee não garante que o mesmo efeito afetaria qualquer outro membro da família; pelo contrário, a descrição de Coetzee sugere-nos que o mais provável seria tal não acontecer. Nada garante, pois, a universalidade propriamente estética do clássico, ou melhor, da experiência intransmissível do alumbramento produzido por ele (refiro-me, com esta palavra tão do agrado de Manuel Bandeira, àquela experiência do "presente absoluto» tão excecionalmente teorizada no nosso tempo por Karl Heinz Bohrer). Ela é da ordem do singular, do imponderável, do contingente. É possível, a este respeito, afirmar que toda a estratégia escolar do humanismo ao longo dos séculos visou criar condições de redução da taxa de imponderabilidade do «encontro com o clássicon; e que tal estratégia nunca alcançou mais do que um sucesso de estima.

(ii) O clássico, que Coetzee tenta inicialmente reduzir a uma fenomenologia desmaterializada, é função de uma materialidade da comunicação. De facto, a epifania de Coetzee só é possível devido à reprodutibilidade técnica: um disco que toca na casa do vizinho. Notemos a conexão paradoxal entre reprodutibilidade técnica e aura, ou seja, o facto de o clássico produzir a sua epifania por meio de uma reprodução: um disco. A experiência de Coetzee é um momento intensamente aurático e que, contudo, e contra Benjamin, pressupõe a reprodução técnica. O clássico é também, pois, uma questão mediática. "Clássicos para todos" - parece ser esse o telos deste devir tecnológico em que o clássico se banaliza no mercado e nos média. Mas, como percebemos nesta versão do encontro com o clássico, a mediatização é condição da própria possibilidade de pensar a universalidade do clássico, hoje. Porque a sua universalidade, postulada durante séculos como princípio descritivo-normativo, é hoje uma simples possibilidade da técnica: no momento em que ela se realiza a baixo custo, o universalismo do clássico torna-se uma banalidade técnico-mercantil. Trata-se apenas de uma política de gestão de redes de produção e distribuição. Como diria Barbara Herrnstein Smith, a pervivência do clássico não necessita de ser 
postulada nos termos do seu funcionamento transcultural e universal, pois trata-se antes do seu funcionamento num sistema comunicacional feito de reenvios e reavaliações crítico-mediáticas permanentes: um sistema apto à produção massificada de «efeitos de reconhecimento» dentro dos quais funciona hoje, em rigor, o clássico. Ou seja, a reivindicação da intemporalidade do clássico, como a sua conceituação enquanto puro princípio desobjetivado, recalca por sistema o facto observável de que tal reivindicação foi historicamente acompanhada por um combate, no terreno das materialidades da comunicação, pela sobrevivência do clássico. É isso, ainda, o Humanismo de Quatrocentos, por via da filologia: uma luta pela forma material dos textos, uma ética do ponto e vírgula como lugares ínfimos mas inevitáveis da sedimentação e ocorrência do clássico.

(iii) A encenação do encontro de Coetzee com o clássico mima uma das versões da clássica encenação do encontro colonial. Regresso a Stuart Hall: «O 'colonialismo' como o 'pós-colonial' diz respeito às formas distintas de 'encenar os encontros' entre as sociedades colonizadoras e seus 'outros'» (Hall, id.). Ao contrário de Eliot, Coetzee não parece ressentir o local da sua cultura, ansiando por uma afiliação numa outra, metropolitana e imperial. Mas, justamente, o encontro com Bach é um momento decisivo da sua Bildung porque o faz perceber que a sua cultura tem lugar em muitos locais, alguns deles insuspeitados antes do encontro com Bach. A possibilidade de um não-lugar para o clássico é aliás a maior dificuldade de um modelo que começa por territorializar quase domesticamente, num jardim das traseiras, a experiência estética - ao mesmo tempo que vê em Bach uma linha de fuga europeia a um contexto local provincial e, em boa verdade, a todos os contextos. O clássico desloca-se e deslocaliza: o jovem Coetzee deixa de ser apenas um jovem sul-africano e passa a ser um vizinho de Bach. Os clássicos podem ser nossos vizinhos, desde que alguém estabeleça previamente um nexo de vizinhança entre todos nós. Mas o local do encontro com o clássico fica para sempre gravado na memória, e no corpo, do sujeito vitimado por ele. Porque a cena epifânica no jardim é uma cena de intensa metafísica da presença: a voz do clássico fala ao sujeito e imobiliza-o, retirando-lhe o sopro. E o sujeito é agora uma estátua pela qual desliza o sopro dessa temporalidade chamada música. É nessa inscrição corporal da aparição do clássico que o seu poder formativo é legível. 
Regresso à questão recorrente nesta leitura do ensaio de Coetzee: se a experiência incondicionada vem primeiro, como defender que o clássico é aquilo que sobrevive à provação dos testes insistentes da instituição? A verdade é que estamos face a uma antinomia que percorre e perturba todo o ensaio de Coetzee (como percorre e perturba toda a teoria contemporânea). Por um lado, a "experiência no jardim», no fundo descrita em termos kantianos: ao ajuizar do belo ou do sublime dela - "A música falava comigo como nunca antes o fizera"-, e embora ela possa parecer uma caraterística do objeto, o autor de facto postula a sua natureza estética, i.e., envolvendo apenas uma representação do objeto no sujeito. A diferença, em relação às anteriores experiências falhadas do sujeito, reside em que desta vez a música lhe consegue falar - o mesmo é dizer, o sujeito consegue ativar as representações de que se faz a "linguagem» musical, podendo então produzir uma cognição ou perceção estética de Bach. Por outro lado, porém, quando se passa ao trabalho da instituição, a música de Bach passa a ser concebida dentro da narrativa da sobrevivência do mais apto - da sobrevivência do objeto mais apto. É difícil não ver aqui uma derrota clamorosa da estética kantiana e o triunfo de um objetualismo aliás contraditório com os propósitos argumentativos perseguidos por Coetzee, já que, no limite, o objetualismo argumenta a eternidade e universalismo da obra em si, dispensando o teste diário da instituição.

Resta um pormenor, e com ele concluo. O jovem Coetzee é vitimado especificamente pelo Cravo bem temperado. Dizer que "Bach é o clássico" é uma ontologização que redunda numa afirmação demasiado generosa para todas as obras do seu corpus que não permitem (ou, pelo menos, tornam muito mais difícil) esta revelação: também em Bach, sejamos francos, há música a metro. O enunciado Bach é o clássico é, em rigor, uma reificação normativa da experiência dificilmente repetível ou transmissível de uma obra particular. Seguramente, quando dizemos que "Camões é o clássico" não estamos a supor que todos os versos do vate estarão à disposição das nossas apetências epifânicas: e não estão porque, entre outras razões, um número razoável deles só sobrevive porque a instituição os testa repetidamente (mas isso não significa, obviamente, que os consiga ressuscitar). Permitam-me que cite, neste momento, um passo de um livro de referência do musicólogo Robbins Landon sobre Vivaldi: 
Creio que as obras mais populares de Vivaldi contêm de facto algo de fascinadamente hipnótico para milhões de ouvintes; e o que torna a situação ainda mais picante é que outras tantas obras de Vivaldi, especialmente as óperas - e, em menor grau, a música sacra - parecem não ter qualquer interesse para o ouvido do século xx. Esta estratificação é muito diversa no caso de Mozart, cujos vários tipos de música - óperas, sinfonias, missas, quartetos, trios, divertimentos, concertos para piano, concertos para violino - são todos igualmente populares. (id.: 10)

O que isto indica é que o autor clássico é o lugar, mais ou menos dramático, de um processo de avaliação, seleção e estratificação do corpus, que, enquanto processo, é obviamente histórico. É este processo que uma expressão como «o meu encontro com o clássico" cancela ou pelo menos limita na sua compreensão. Aquilo a que chamamos hoje Bach, como aquilo a que chamamos hoje Vivaldi ou Camões, é, antes de mais, uma hermenêutica histórica do corpus. Que, tratando-se de clássicos - i.e., entidades institucionais -, postula previamente (é esse o seu pré-conceito) a sua homogeneidade, organicidade e inscrição numa sequência fundada por outros clássicos. Nesse sentido, o encontro de Coetzee com O Cravo bem Temperado não é o encontro com o clássico, mas sim um encontro com a música, ou melhor, com uma forma muito particular de linguagem musical. Ninguém se encontra com o clássico no jardim das traseiras de uma moradia suburbana - do mesmo modo que ninguém pode deixar de se encontrar com $o$ clássico quando ouve O Cravo bem Temperado numa sala de concerto.

Est modus in locis. 


\section{BIBLIOGRAFIA}

COETZEE, J. M. (2001) "What Is A Classic? A Lecture”, in Stranger Shores. Essays 1986-1999, Londres, Vintage, 1-19.

HALL, Stuart (2003) "Quando foi o pós-colonial? Pensando no limite", in Da Diáspora. Identidades e Mediações Culturais, (org. de Liv Sovik), Belo Horizonte e Brasília, Editora UFMG e Representação da Unesco no Brasil, pp. 101-128.

LANDON, H. C. Robbins (1993) Vivaldi. Voice of the Baroque, Londres, Thames and Hudson. 